\title{
BRPKM
}

Buletin Riset Psikologi dan Kesehatan Mental

http://e-journal.unair.ac.id/index.php/BRPKM

e-ISSN: 2776-1851

ARTIKEL PENELITIAN

\section{Hubungan Psikopati dan Penerimaan Mitos Pemerkosaan pada Laki-laki Dewasa Awal}

\author{
LENY APRILIA \& ENDANG R. SURJANINGRUM* \\ Fakultas Psikologi Universitas Airlangga
}

\begin{abstract}
ABSTRAK
Angka kekerasan seksual di Indonesia meningkat dari tahun ke tahun, namun tidak semua korban melaporkan kejadian yang dialaminya karena adanya victim blaming di masyarakat yang akan dijelaskan lebih lanjut pada penelitian ini. Penelitian ini bertujuan untuk mengetahui apakah terdapat hubungan antara psikopati dengan penerimaan mitos pemerkosaan pada laki-laki dewasa awal. Penelitian dilakukan pada sampel yang terdiri atas 130 laki-laki dengan rentang usia 18-40 tahun dan berdomisili di Jawa Timur. Psikopati diukur dengan Levenson Self-Report Psychopathy Scale, sedangkan penerimaan mitos pemerkosaan diukur dengan Illinois Rape Myth Acceptance Scale Short Form. Teknik analisis data yang digunakan adalah uji korelasi product moment Pearson. Hasil dari analisis data menunjukkan terdapat korelasi positif yang signifikan antara psikopati primer dengan penerimaan mitos pemerkosaan $(\mathrm{r}=0,335, \mathrm{p}=0,000)$ dan psikopati sekunder dengan penerimaan mitos pemerkosaan $(r=0,308, p=0,000)$ yang artinya semakin tinggi psikopati pada individu, berarti semakin tinggi pula penerimaan mitos pemerkosaannya.
\end{abstract}

Kata kunci: dewasa awal, laki-laki, penerimaan mitos pemerkosaan, psikopati

\begin{abstract}
The amount of violence in Indonesia has increased year after year, but not all the victims reported the incidents because of the existence of victim-blaming in society. This study aims to determine whether there is a relationship between psychopathy and rape myth acceptance in early adult men. The study was conducted on a sample consisting of 130 men aged 18-40 years and domiciled in East Java. Psychopathy was measured by the Levenson Self-Report Psychopathy Scale, while rape myth acceptance was measured by the Illinois Rape Myth Acceptance Scale Short Form. Data analysis was performed using Pearson's product moment. The results showed there was a significant positive correlation between primary psychopathy and rape myth acceptance $(r=0.335, p=0.000)$ and secondary psychopathy with rape myth acceptance $(r=0.308, p=0.000)$ which means the higher psychopathy in individuals, means the higher the rape myth acceptance.
\end{abstract}

Keywords: early adult, men, rape myth acceptance, psychopathy 


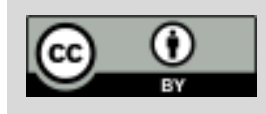

Naskah ini merupakan naskah dengan akses terbuka dibawah ketentuan the Creative Common Attribution License (CC-BY-4.0) (http://creativecommons.org/licenses/by/4.0), sehingga penggunaan, distribusi, reproduksi dalam media apapun atas artikel ini tidak dibatasi, selama sumber aslinya disitir dengan baik.

\section{PEN D A H U L U A N}

Angka kasus kekerasan seksual di Indonesia yang dialami oleh perempuan tidaklah sedikit. Pada tahun 2017, Badan Pusat Statistik merilis hasil survei nasional bahwa satu dari tiga perempuan usia 15-64 tahun pernah mengalami kekerasan fisik atau seksual selama hidupnya (Badan Pusat Statistik, 2017). Jumlah kasus kekerasan terhadap perempuan pada tahun 2019 sebesar 431.471, jumlah ini meningkat dibandingkan dengan tahun sebelumnya yang berjumlah 406.178. Berdasarkan data-data yang terkumpul tersebut jenis kekerasan terhadap perempuan yang paling menonjol sama seperti tahun sebelumnya adalah KDRT/RP (ranah personal) yang mencapai angka 75\% (11.105 kasus). Ranah pribadi paling banyak dilaporkan dan tidak sedikit diantaranya mengalami kekerasan seksual. Posisi kedua di ranah komunitas/publik dengan persentase 24\% (3.602) dan terakhir adalah di ranah negara dengan persentase $0.1 \%$ (12 kasus). Pada ranah KDRT/RP kekerasan yang paling menonjol adalah kekerasan fisik 4.783 kasus (43\%), menempati peringkat pertama disusul kekerasan seksual sebanyak 2.807 kasus (25\%), psikis 2.056 (19\%) dan ekonomi 1.459 kasus (13\%). Pada ranah publik dan komunitas kekerasan terhadap perempuan tercatat 3.602 kasus. 58\% kekerasan terhadap perempuan di Ranah Publik atau Komunitas adalah adalah Kekerasan Seksual yaitu Pencabulan (531 kasus), Perkosaan (715 kasus) dan Pelecehan Seksual (520 kasus). Sementara itu persetubuhan sebanyak 176 kasus, sisanya adalah percobaan perkosaan dan persetubuhan (Komnas Perempuan, 2020).

Di ranah KDRT/RP dan ranah komunitas jumlah paling tinggi usia pelaku ada di kisaran 25-40 dengan tingkat pendidikan tertinggi baik korban maupun pelaku adalah lulus sekolah menengah atas. Hal tersebut menunjukkan bahwa baik pelaku dan korban kekerasan berada dalam usia yang produktif (Komnas Perempuan, 2020). Dari data di atas dapat diambil kesimpulan bahwa kekerasan seksual bukanlah masalah yang sepele mengingat jumlah kasus yang meningkat setiap tahunnya dan kekerasan seksual merupakan jenis kekerasan terbanyak kedua setelah kekerasan fisik. Kemudian, pada Maret 2021 Komnas Perempuan pada tahun 2021 melaporkan bahwa angka kekerasan terhadap perempuan sepanjang tahun 2020 turun menjadi 299.911 kasus dari tahun sebelumnya yaitu 431.471 kasus. Hal ini terjadi karena pengembalian kuisoner yang disebar oleh Komnas Perempuan menurun hampir 100\%. Namun, sebagaimana yang terjadi bahwa tidak semua korban kekerasan seksual melaporkan kejadian yang dialaminya (Komnas Perempuan, 2021). Survei daring tahun 2016 yang dilakukan oleh Lentera Sintas Indonesia dan Magdalene.co serta difasilitasi oleh Change.org Indonesia menemukan bahwa 93\% penyintas kekerasan seksual tidak pernah melaporkan kasusnya ke penegak hukum dengan alasan yang beragam, tetapi 63 persen responden menyebutkan "malu" sebagai alasan utama mereka dan 6 persen yang melaporkan pada akhirnya menyaksikan pelaku bebas dari jerat hukum (Asmarani, 2016).

Istilah yang digunakan untuk menjelaskan perilaku menyalahkan korban disebut dengan Victim blaming yang juga dikenal dengan istilah Blaming the Victim, yang dalam konteks kekerasan seksual, BTV mengacu pada kecenderungan untuk membuat korban bertanggung jawab atas serangan yang terjadi kepada mereka (Crippen, 2015; Gravelin dkk., 2019). Victim blaming dalam menentukan kesalahan, sering mengaitkan serangan yang dialami korban dengan adanya pengaruh narkoba atau alkohol, daya tarik korban dan pelaku, sejauh mana korban tidak berusaha melawan pelaku, dan baju yang digunakan oleh korban (Gravelin dkk., 2019). Fenomena menyalahkan korban ini dapat dijelaskan melalui

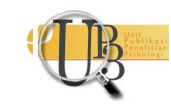


penerimaan mitos pemerkosaan atau rape myth acceptance. Penerimaan mitos pemerkosaan merupakan sikap dan keyakinan yang umumnya salah tetapi dipegang secara luas dan terus-menerus, dimaksudkan untuk menyangkal dan membenarkan serangan seksual laki-laki terhadap perempuan. Tentunya mitos pemerkosaan ini dapat mendorong budaya menyalahkan korban karena memperkuat keyakinan bahwa korbanlah yang harus disalahkan dan di sisi lain meminimalkan serta membenarkan tindakan pelaku. Mitos pemerkosaan berbeda-beda di antara masyarakat dan budaya. Namun, secara konsisten mengikuti pola tertentu yaitu menyalahkan korban, mengungkapkan ketidakpercayaan pada klaim pemerkosaan, membebaskan pelaku dan menyinggung bahwa hanya beberapa jenis perempuan yang diperkosa (Grubb \& Turner, 2012).

Penelitian menunjukkan bahwa laki-laki lebih mendukung mitos pemerkosaan daripada wanita (Hayes dkk., 2013). Laki-laki cenderung untuk menyalahkan korban yang mengalami pelecehan seksual daripada perempuan. Mereka juga mendukung pandangan negatif lainnya tentang korban terutama korban perempuan. Hal ini karena perempuan dan laki-laki memiliki sikap dan kepercayaan yang berbeda tentang pelecehan seksual dan bagaimana kejadian itu mempengaruhi perempuan (Bongiorno dkk., 2020). Mereka juga cenderung berpikir bahwa korban menerima kesenangan pada saat perkosaan terjadi dan dengan demikian korban juga harus bertanggung jawab atas kejadian tersebut. Pemikiran seperti ini yang berperan dalam mitos pemerkosaan karena menganggap. Terdapat penelitianpenelitian tentang penerimaan mitos pemerkosaan. Penelitian-penelitian tersebut mencoba mengaitkan penerimaan mitos pemerkosaan dengan psikopati. Psikopati ditandai dengan adanya pola hubungan interpersonal yang bersifat manipulatif, kurangnya rasa empati, perilaku impulsif bahkan dianggap sebagai salah satu kepribadian yang paling merusak serta menunjukkan korelasi yang kuat dengan perilaku kriminalitas, residivisme (mengulangi perilaku yang sama), dan agresi (Gordts dkk., 2017).

Penelitian tentang hubungan antara psikopati dan penerimaan mitos pemerkosaan pertama kali diteliti oleh (Mouilso \& Calhoun, 2013) yang dilakukan kepada mahasiswa laki-laki perguruan tinggi. Penelitian tersebut menguji hubungan antara penerimaan mitos pemerkosaan, psikopati, dan perilaku agresi seksual. Hasilnya cukup konsisten dengan pendapat bahwa mitos pemerkosaan berfungsi untuk menetralkan norma-norma sosial yang melarang perilaku agresi seksual. Hal ini sesuai dengan pernyataan sebelumnya bahwa penerimaan mitos pemerkosaan bisa digunakan untuk membenarkan dan mendorong terjadinya bentuk-bentuk agresi seksual yang parah.

Oleh karena itu, penelitian ini menjadi penting untuk dilaksanakan. Ketika lebih memahami fenomena victim blaming yang merupakan bentuk dari adanya kepercayaan terhadap mitos pemerkosaan. Diharapkan nantinya dapat merumuskan solusi yang tepat. Kemudian atas pempertimbangkan dampak yang ditimbulkan akibat adanya budaya menyalahkan korban, perlu untuk memahami bagaimana fenomena menyalahkan korban kekerasan seksual tersebut terjadi. Oleh karena itu, penelitian ini bertujuan untuk mengungkap hubungan antara psikopati dan penerimaan mitos pemerkosaan pada laki-laki dewasa awal.

\section{Desain Penelitian}

\section{E T O D E}

Penelitian ini menggunakan metode pendekatan kuantitatif dengan tipe penelitian eksplanatori. Pengumpulan data menggunakan teknik survei. 


\section{Partisipan}

Partisipan pada penelitian ini adalah laki-laki dewasa awal yang berusia 18-40 tahun yang berdomisili di Jawa Timur. Teknik sampling yang digunakan penulis adalah teknik sampling non-random sampling dengan cara purposive sampling. Kuesioner pada penelitian ini disebarkan melalui media sosial dan aplikasi instant messaging. Partisipan bersedia untuk membantu mengisi kuesioner dengan menyetujui informed consent yang diberikan. Partisipan dalam penelitian ini berjumlah 30 orang dengan rentang usia antara 18-40 tahun yang didominasi oleh usia 21 tahun dengan nilai SD sebesar 2,14.

\section{Pengukuran}

Pengukuran pada penelitian ini menggunakan dua alat ukur. Psikopati diukur menggunakan Levenson Self Report Psychopathy Scale (LSRP) yang dikembangkan oleh Michael R. Levenson pada tahun 1995 yang terdiri dari 26 item dengan rentang skala 1 sampai 4 yaitu $(1=$ sangat tidak setuju, 2 = agak tidak setuju, 3 = agak setuju, dan 4 = sangat setuju). Nilai reliabilitas berdasarkan analisis teknik Cronbach's alpha untuk psikopati primer adalah sebesar 0,77 dan nilai untuk psikopati sekunder sebesar 0,56. Penerimaan mitos pemerkosaan diukur menggunakan Illinois Rape Myth Acceptance Scale Short Form (IRMA-SF) yang terdiri dari 20 item dengan menggunakan skala likert skala likert 7 poin, dimana 1= sangat tidak setuju dan $7=$ sangat setuju dengan koefisien reliabilitas yang cukup baik $(\alpha=0.89)$.

Sebelum melakukan uji korelasi, penulis melakukan uji asumsi. Hasil uji asumsi menunjukkan data berdistribusi normal, tidak menunjukkan gejala heterokedastisitas, serta terdapat hubungan yang linear dari kedua variabel.

\section{Analisis Data}

Pembuktian hipotesis dilakukan melalui uji korelasi dengan teknik statistik product moment dari pearson dengan bantuan IBM SPSS Statistic 23. Uji korelasi dilakukan untuk mengetahui hubungan antara kedua variabel dan tingkat korelasinya.

\section{HAS I L P E N EL I T I A N}

Hasil analisis data menunjukkan bahwa setelah dilakukan uji korelasi product moment pearson, psikopati primer secara signifikan berkorelasi positif dengan penerimaan mitos pemerkosaan, $r=0,335$, $\mathrm{p}<0,01$. Psikopati sekunder juga secara signifikan berkorelasi positif dengan penerimaan mitos pemerkosaan, $r=0,308, \mathrm{p}<0,01$. Artinya, semakin tinggi skor psikopati primer dan sekunder pada individu, kemungkinan ia memiliki kepercayaan yang tinggi pula terhadap penerimaan mitos pemerkosaan.

\section{I S K U S I}

Penelitian ini bertujuan untuk menguji apakah terdapat hubungan antara psikopati dan penerimaan mitos pemerkosaan pada laki-laki dewasa awal. Hasil dari penelitian ini adalah psikopati yang dibagi menjadi dua subtipe yaitu psikopati primer dan psikopati sekunder berkorelasi positif secara signifikan dengan variabel penerimaan mitos pemerkosaan. Hasil ini sesuai dengan hasil penelitian yang dilakukan oleh (Mouilso \& Calhoun, 2013). Namun terdapat catatan yaitu korelasi pada komponen psikopati masing-masing memiliki skor yang berbeda. Skor korelasi masuk dalam kategori sedang yaitu antara psikopati primer dengan penerimaan mitos pemerkosaan sebesar 0,335 sedangkan korelasi psikopati sekunder dengan penerimaan mitos pemerkosaan adalah sebesar 0,308. 
Manifestasi psikopati memiliki karakteristik yang berbeda pada tiap sub tipenya. Psikopati primer memiliki fitur tidak berperasaan, manipulatif, egois, dan tidak jujur (Rogoza \& Cieciuch, 2018). Selain itu juga tidak bertanggung jawab, kegagalan untuk belajar dari pengalaman, dan memiliki ciri-ciri utama yang tampak adaptif atau setidaknya non-patologis seperti memiliki kecemasan yang rendah, pesona interpersonal, tidak adanya pemikiran irasional (Cleckley, 1976 dalam Vaughn dkk., 2009). Jika dikaitkan dengan penerimaan mitos pemerkosaan, psikopati primer berkaitan dengan emosi pro sosial yang rendah. Pada konteks kekerasan seksual, individu memiliki empati yang rendah terhadap korban bahkan cenderung menyalahkan korban daripada pelaku. Selain itu, rendahnya rasa bersalah juga menjadi ciri khas yang dapat memengaruhi rendahnya rasa tanggung jawab terhadap orang lain. Individu kemungkinan juga memiliki cara yang berbeda dalam mengambil keputusan karena memiliki masalah regulasi emosi dalam perilaku moral (Brewer dkk., 2019). Adanya karakteristik manipulatif pada psikopati juga dikaitkan dengan kepercayaan terhadap mitos pemerkosaan. Individu yang manipulatif akan membuat orang lain atau korban merasa bersalah dan harus bertanggung jawab atas kejadian yang menimpanya dengan cara mengkritik perilaku korban seperti ungkapan bahwa korban pasti mengenakan pakaian yang provokatif sehingga mereka pantas diperkosa (Mouilso \& Calhoun, 2013)

Psikopati sekunder ditandai sebagai perilaku antisosial di bawah pengaruh gangguan emosional, dimanifestasikan oleh impulsif (Levenson, dkk., 1995 dalam Rogoza \& Cieciuch, 2018) serta berisiko lebih besar untuk terlibat dalam perilaku merusak diri sendiri dan orang lain, seperti penyalahgunaan narkoba, adanya ide untuk bunuh diri, dan perilaku agresi (Vaughn dkk., 2009). Seseorang yang memiliki karakteristik psikopati sekunder memiliki kepercayaan terhadap penerimaan mitos pemerkosaan yang digunakan sebagai bagian dari kecenderungan yang lebih besar untuk memaafkan perilaku agresif dan antisosial mereka. Pada penerimaan mitos pemerkosaan terdapat dimensi rape is a trivial event yang mana individu percaya bahwa pemerkosaan adalah kejadian yang sepele. Secara tidak langsung kepercayaan ini menyangkal adanya dampak fisik maupun emosi korban dan mencoba untuk menetralkan larangan-larangan yang ada pada masyarakat (Mouilso \& Calhoun, 2013). Hal ini sesuai dengan pernyataan Burt (1980) dalam Mouilso \& Calhoun (2013) bahwa mitos pemerkosaan berfungsi sebagai pelepas atau penawar psikologis yang memungkinkan laki-laki untuk membenarkan pelanggaran yang dilakukannya dengan menyalahkan korban.

\section{S I M P U L A N}

Penelitian ini bertujuan untuk memahami fenomena menyalahkan korban di masyarakat dengan dengan cara mengetahui hubungan antara sikap penerimaan mitos pemerkosaan dengan psikopati. Berdasarkan hasil analisis data yang dilakukan, dapat ditarik kesimpulan bahwa psikopati yang dibedakan menjadi psikopati primer dan psikopati sekunder memiliki korelasi positif yang signifikan dengan penerimaan mitos pemerkosaan pada laki-laki dewasa awal. Dari hasil tersebut dapat disimpulkan bahwa semakin tinggi psikopati pada individu pada seseorang semakin tinggi pula sikap penerimaan mitos pemerkosaannya.

Adapun saran untuk penelitian selanjutnya adalah melakukan pendataan lebih lanjut mengenai pengalaman subjek terutama berkenaan dengan pengalaman melakukan atau mengalami kekerasan seksual. Hal ini dapat membantu penulis untuk lebih memahami secara mendalam dan mengetahui apakah terdapat perbedaan antara mereka yang pernah melakukan kekerasan seksual dengan mereka yang tidak pernah melakukan kekerasan seksual. Selain itu juga untuk mengetahui apakah terdapat perbedaan antara mereka yang mengalami kekerasan seksual dan mereka yang tidak mengalami kekerasan seksual. Sehingga penulis dapat mengontrol bias jawaban subjek penelitian. Penelitian 
selanjutnya juga dapat menggunakan sampel yang berbeda dan mencoba menggunakan variabel lain untuk memprediksi kecenderungan perilaku yang berkaitan dengan psikopati ataupun penerimaan mitos pemerkosaan, kemudian menganalisis secara detail per dimensi setiap variabel agar mengetahui lebih spesifik.

Selanjutnya saran bagi profesional kesehatan mental adalah bergerak bersama pemerintah untuk memberikan psikoedukasi mengenai kekerasan seksual berserta dampaknya untuk meningkatkan kesadaran masyarakat serta bagaimana cara mencari bantuan profesional untuk korban. Salah satunya adalah bisa melakukan kampanye melalui media sosial atau mengadakan webinar. Kemudian penting juga dalam mengembangkan intervensi yang efektif untuk yang berkaitan dengan masalah psikologis baik untuk korban maupun pelaku serta melakukan pendampingan dengan maksimal terhadap korban kekerasan seksual sebagai upaya rehabilitasi.

Saran selanjutnya yaitu untuk pembuat kebijakan dapat mengubah sikap dan kepercayaan masyarakat dengan meningkatkan edukasi bahwa kekerasan seksual adalah masalah yang serius. Salah satunya adalah dengan melakukan kampanye di media sosial karena mudah dijangkau atau dengan mengadakan webinar. Selain itu, penting untuk menyediakan tempat pelayanan kesehatan mental secara merata di berbagai daerah yang dapat dijangkau oleh masyarakat dari berbagai golongan serta mengkaji kembali kebijakan atau peraturan hukum untuk pelaku kekerasan seksual serta melakukan pendampingan terhadap pelaku maupun korban.

Untuk pekerja di bidang hukum, hal-hal yang dapat dilakukan adalah bekerja sama dengan profesional kesehatan mental dalam melakukan pendampingan terhadap korban kekerasan seksual ketika menjalankan proses hukum dan memaksimalkan kerjasama dengan beberapa pihak seperti kepolisian, kejaksaan, pengadilan, ataupun masyarakat dalam upaya memberikan perlindungan hukum bagi korban kekerasan seksual.

\section{U C A P A N T ER I MAKASIH}

Penulis mengucapkan terima kasih kepada Allah SWT. Penulis juga mengucapkan terima kasih kepada keluarga, teman, dan seluruh pihak yang sudah mendukung penulis dalam menyusun tugas akhir skripsi ini.

\section{DEKLARASI POTENSI TERJADINYA KONFLIK KEPENTINGAN}

Leny Aprilia dan Endang R. Surjaningrum tidak bekerja, menjadi konsultan, memiliki saham, atau menerima dana dari perusahaan atau organisasi manapun yang mungkin akan mengambil untung dari diterbitkannya naskah ini.

\section{PUSTAKA ACUAN}

Asmarani, D. (2016). 93 Persen Penyintas Tak Laporkan Pemerkosaan yang Dialami: Survei. https://magdalene.co/story/93-persen-penyintas-tak-laporkan-pemerkosaan-yang-dialamisurvei

Badan Pusat Statistik. (2017). SPHPN 2016: Prevalensi Kekerasan Terhadap Perempuan di Indonesia. In Badan Pusat Statistik (BPS) (Issue 29/03).

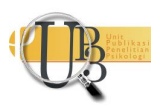


https://www.bps.go.id/pressrelease/2017/03/30/1375/satu-dari-tiga-perempuan-usia-15--64-tahun-pernah-mengalami-kekerasan-fisik-dan-atau-seksual-selama-hidupnya.html

Bongiorno, R., Langbroek, C., Bain, P. G., Ting, M., \& Ryan, M. K. (2020). Why Women Are Blamed for Being Sexually Harassed: The Effects of Empathy for Female Victims and Male Perpetrators. Psychology of Women Quarterly, 44(1), 11-27. https://doi.org/10.1177/0361684319868730

Brewer, G., Lyons, M., Perry, A., \& O’Brien, F. (2019). Dark Triad Traits and Perceptions of Sexual Harassment. Journal of Interpersonal Violence, 1-15. https://doi.org/10.1177/0886260519827666

Crippen, M. (2015). Theories of Victim Blame. 1-28.

Gordts, S., Uzieblo, K., Neumann, C., Van den Bussche, E., \& Rossi, G. (2017). Validity of the Self-Report Psychopathy Scales (SRP-III Full and Short Versions) in a Community Sample. Assessment, 24(3), 308-325. https://doi.org/10.1177/1073191115606205

Gravelin, C. R., Biernat, M., \& Baldwin, M. (2019). The impact of power and powerlessness on blaming the victim of sexual assault. Group Processes and Intergroup Relations, 22(1), 98-115. https://doi.org/10.1177/1368430217706741

Grubb, A., \& Turner, E. (2012). Attribution of blame in rape cases: A review of the impact of rape myth acceptance, gender role conformity and substance use on victim blaming. Aggression and Violent Behavior, 17(5), 443-452. https://doi.org/10.1016/j.avb.2012.06.002

Hayes, R. M., Lorenz, K., \& Bell, K. A. (2013). Victim Blaming Others: Rape Myth Acceptance and the Just World Belief. Feminist Criminology, 8(3), 202-220. https://doi.org/10.1177/1557085113484788

Komnas Perempuan. (2020). Catatan Tahunan Kekerasan Terhadap Perempuan Tahun 2019. http://nasional.kompas.com/read/2010/12/16/04425515/

Komnas Perempuan. (2021). Catatan Tahunan Kekerasan Terhadap Perempuan Tahun 2020.

Mouilso, E. R., \& Calhoun, K. S. (2013). The role of rape myth acceptance and psychopathy in sexual assault perpetration. Journal of Aggression, Maltreatment and Trauma, 22(2), 159-174. https://doi.org/10.1080/10926771.2013.743937

Rogoza, R., \& Cieciuch, J. (2018). Dark Triad traits and their structure: An empirical approach. Current Psychology, 1-16. https://doi.org/10.1007/s12144-018-9834-6

Vaughn, M. G., Edens, J. F., Howard, M. O., \& Smith, S. T. (2009). An investigation of primary and secondary psychopathy in a statewide sample of incarcerated youth. Youth Violence and Juvenile Justice, 7(3), 172-188. https://doi.org/10.1177/1541204009333792 